\title{
Acute energy intake and appetite responses following high-intensity interval exercise in 12-13 year old boys and girls
}

\author{
J. Varley ${ }^{1}$, M. Moore ${ }^{2}$ and C. A. Williams ${ }^{1}$ \\ ${ }^{1}$ Children's Health and Exercise Research Centre, St Luke's Campus, University of Exeter, Exeter, EXI 2L, UK and \\ ${ }^{2}$ School of Health Professionals, Plymouth University, Plymouth, PL6 8BH, UK
}

Following exercise, gender differences in energy intake (EI) and appetite have been reported in adult literature. High intensity exercise suppresses appetite in males but not females ${ }^{(1,2)}$ and significantly increases EI in females but not males ${ }^{(1,2)}$. Investigating gender differences in EI and appetite following exercise in the paediatric population has not been performed in normal weight children, and only once in obese adolescents ${ }^{(3)}$. Therefore, it is important to distinguish gender effects at a young age as maintaining energy balance post exercise is important for growth.

Twenty boys and 18 girls (12-13 y) participated in this study. In the control condition no exercise was permitted from arrival for breakfast until after lunch had been consumed. The exercise condition involved sprint cycling for $10 \mathrm{~s}$ followed by $110 \mathrm{~s}$ slow active recovery, repeated 15 times for a total duration of $30 \mathrm{~min}$. Sixty minutes post completion of the exercise an ad libitum lunch was offered and EI was recorded. Lunch consisted of sandwiches and cake offered in excess and with homogenised macronutrient compositions ${ }^{(4)}$. Differences in EI at lunch relative to exercise energy expenditure were calculated. Appetite ratings of hunger, fullness and prospective consumption were rated 6 times throughout the day through visual analogue scales ${ }^{(5)}$.

There were no significant differences in EI between conditions for either gender $(p>0.05)$. The mean EI difference between conditions was not representative of individual data; Figure 1a and 1b. EI compensation was not significantly correlated with any anthropometric measures for boys $\left(R^{2}=0.31, p=0.64\right)$ or girls $\left(R^{2}=0.16, p=0.95\right)$.
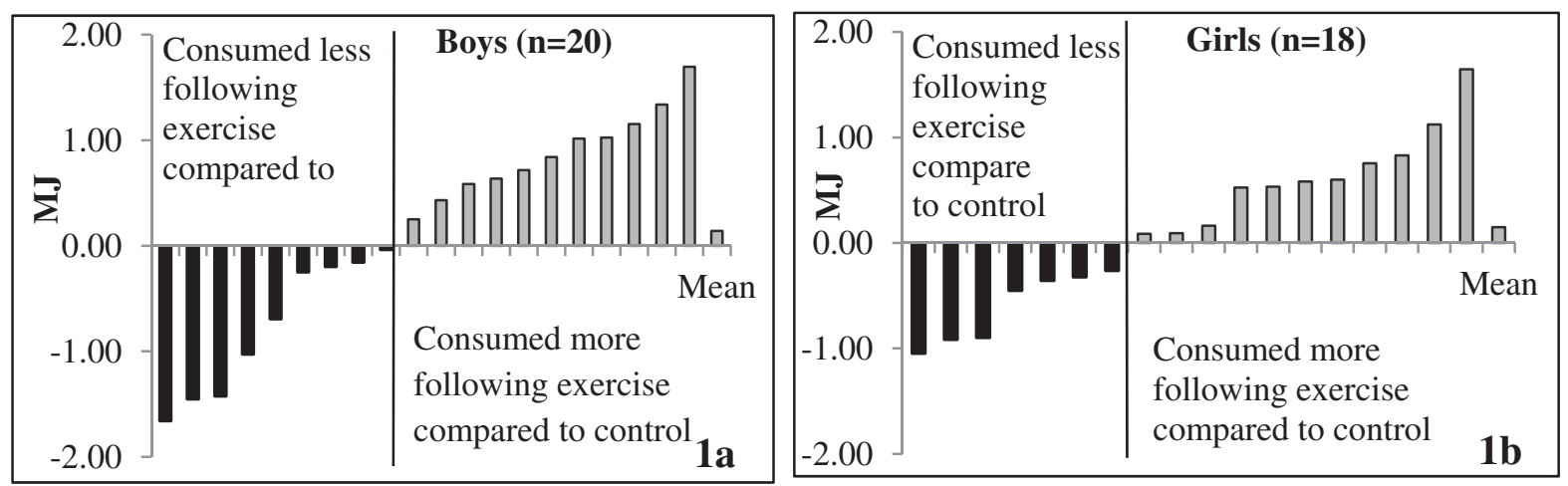

Figure 1a and 1b. Individual differences for energy intake in MJ on the exercise condition when compared to sedentary condition in boys and girls.

Prospective consumption was found to have a significant interaction over time when contrasted between conditions for the boys. The boys expressed a reduction in their desire to eat following exercise, similar to that found in adult males ${ }^{(2)}$. Hunger and fullness showed no significant interactions for either gender. High intensity interval exercise reduced the desire to eat in boys but not girls. This reduction did not track into changes of EI for the subsequent meal. This is the first study to report gender differences in appetite following exercise in children and requires further elucidation.

We would like to acknowledge PhD studentship finding from Kellogg Ltd UK.

1. Thompson D, Wolfe L \& Eikelboom R (1998) Med Sci Sports Exerc 20, 222-7.

2. Pomerleau M, Imbeault P, Parker T \& Doucet E (2004) Am J Clin Nutr 80, 1230-1236.

3. Thievel D, Isacco L, Taillardat M et al. (2011) Appetite 56, 658-661.

4. Poppitt S, McCormack D \& Buffenstein, R (1998) Physiol Behav 64, 279-85.

5. Flint A, Raben A, Blundell J \& Astrup A (2000) Int J Obes Relat Metab Disord 24, 38-48. 